\title{
Tratamento gráfico de informação para vazão e precipitação utilizando a técnica de fichário-imagem
}

\author{
Chart treatment information for flow and precipitation using the technique of Binder-image \\ EDINÉIA VILANOVA GRIZIO-ORITA*, DEISE REGINA ELIAS QUEIROZ**
}

*Universidade Estadual de Ponta Grossa - PR; email: edineia_grizio@hotmail.com

**Universidade Estadual de Maringá - PR

\begin{abstract}
Resumo
A informação visual, não é nem natural e nem espontânea porque possui uma linguagem própria que precisa ser apreendida. Ela para ser realmente compreendida, requer uma aprendizagem. O presente estudo procura enfocar a importância da imagem nas representações gráficas. Procura discutir a semiologia gráfica como um importante recurso para a cartografia. A questão da informação e da percepção visual são colocadas como recursos que requerem um aprendizado, pois a linguagem gráfica é um sistema de signos com significados e significantes. Nesse trabalho, será aplicado a técnica do fichário-imagem para o entendimento de algumas situações de precipitação e vazão, facilitando dessa forma a análise das informações. E foi possível concluir que, o sistema fluvial é marcado por uma resposta lenta à precipitação, o que pode ser explicado pela forma da bacia, pela baixa declividade das vertentes, e pela grande capacidade de armazenamento das coberturas superficiais.
\end{abstract}

Palavras-chave: percepção visual; fichário-imagem; vazão; precipitação

\begin{abstract}
The visual information is neither natural and nor spontaneous because has an own language that must be seized. It, to be really understood, requires a learning. This study aims to focus on the importance of image in graphics representations. It discusses the graphic semiology as an important resource for mapping. The issue of information and visual perception are placed as resources that require a special study because the graphic language is a system of signs with meanings and significance. In this paper, we applied the technique of Binder-image to understand some situations of rainfall and flow, thereby facilitating analysis of the information. It was concluded that the river system is marked by a slow response to rainfall, which can be explained by the shape of the basin, the low slope of the sides, and the large storage capacity of roof surface.
\end{abstract}

Key-words: visual perception; image-binder, flow, precipitation

\section{Introdução}

Estudiosos de diversas áreas do conhecimento científico, movidos por preocupações diferentes e por diferentes caminhos, procuram analisar tanto as imagens com conotações abstratas, como concretas.

A imagem gráfica, como uma imagem concreta, evoluiu muito nos últimos quarenta anos. Segundo Bertin(1973), a imagem gráfica é a forma visual significativamente percebida em um só golpe de vista, em um instante de tempo através da percepção.

É importante lembrar que na medida em que o usuário deixa de ser passivo diante de uma mensagem comunicada através de uma imagem, na tentativa de compreendê-la, estabelece-se um processo de decodificação. Assim, uma das formas de estudo das imagens refere-se a análise de seus elementos e as relações entre suas partes.

A técnica que será utilizada nesse trabalho será o fichário-imagem que é um dos instrumentos para tratamento gráfico de dados, criado por "Graphique", disciplina sistematizada no Laboratoire de Graphique, da Ecole dês Hautes Etudes em Sciences Sociales, de Paris, cujo fundador, Jacques Bertin, foi o primeiro a lançar as bases de uma estrutura da linguagem gráfica.

Enquanto os gráficos tradicionais dão prioridade ao "estético", e frequentemente transgridem as propriedades naturais da percepção, para a Graphique uma representação gráfica tem por objeto fazer aparecer as relações que existem entre os elementos que são 
representados prévia e rigorosamente, de modo a garantir a monossemia que envolve a Graphique (ARAÚJO \& CARDOSO, 1986).

Para a adequada compreensão da evolução do rio Paraguai Superior, em especial a área a ser estudada (Barra do Bugres a Cáceres), é necessário tratar os dados para compreendê-los e revelar a informação que possam conter, agrupar os anos semelhantes e compreender a relação vazão-precipitação.

\section{Localização da área de estudo}

A área de estudo está situada entre a cidade de Barra do Bugres-MT e a foz do rio Sepotuba, e limita-se entre as coordenadas 1502'48' e 1502'24" de latitude sul e 570ㅜㄴ $48^{\prime \prime}$ e 57은 $48^{\prime \prime}$ de longitude oeste (Figura 1).

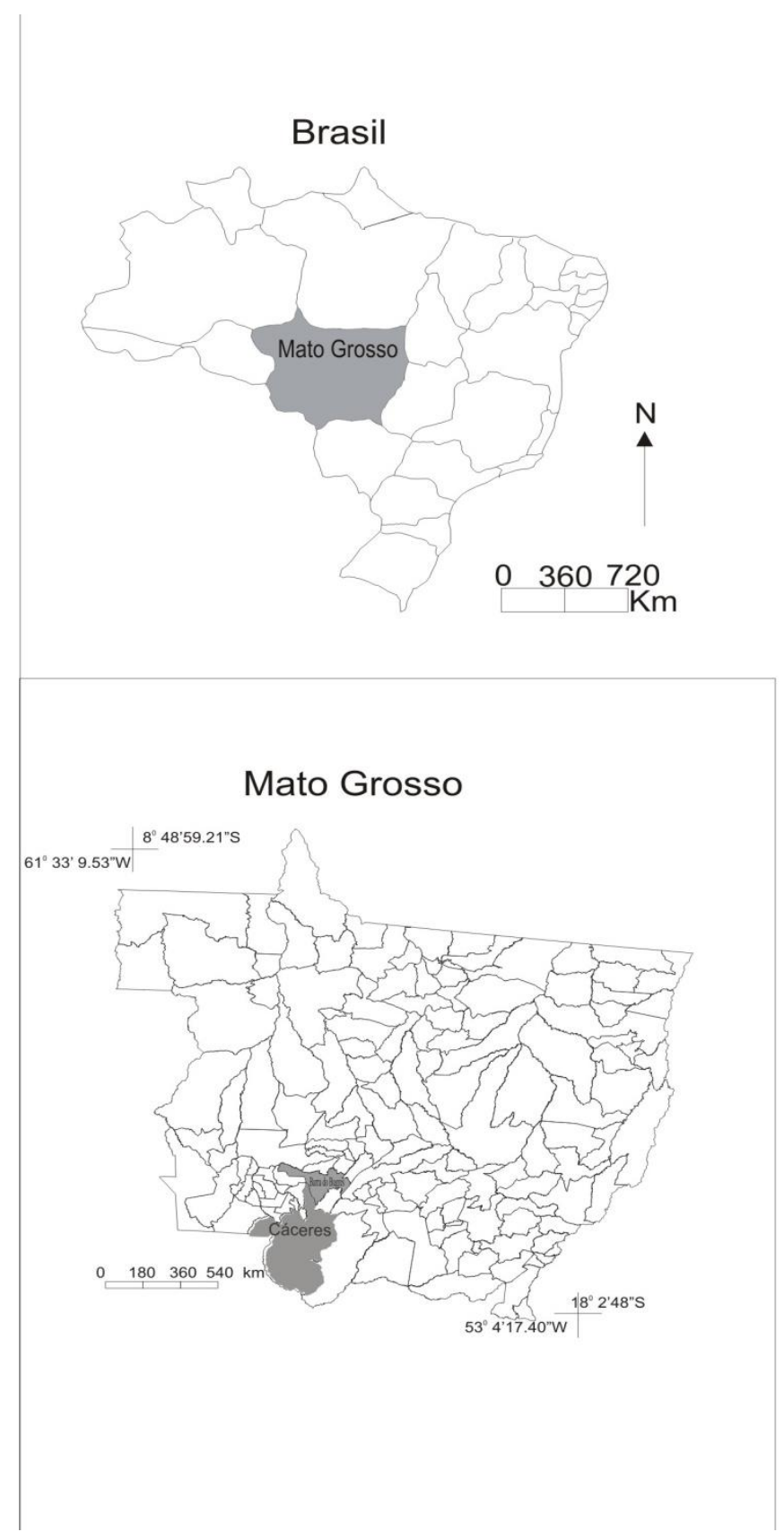

\section{Metodologia}

O débito, a vazão ou a descarga é uma das principais variáveis que caracterizam um rio e é a quantidade de água que passa através de uma seção transversal, por unidade de tempo. O débito fluvial é considerado uma variável estocástica porque depende ou resulta de variáveis aleatórias (TUCCI, 2002) e por isso é bastante variável no tempo e no espaço.

A variabilidade representada pela dinâmica de águas baixas e altas tem como causa a combinação de diversos elementos da bacia hidrográfica ou fatores que ocorrem na mesma, tais como: condições de precipitação; evapo transpiração; radiação solar; geologia; geomorfologia (declividade, comprimento da vertente); solos; cobertura vegetal; uso do solo, e ação antrópica (TUCCI, 2002), além da forma da bacia, de acordo com Villela e Mattos (1975).

\section{Área de estudo}

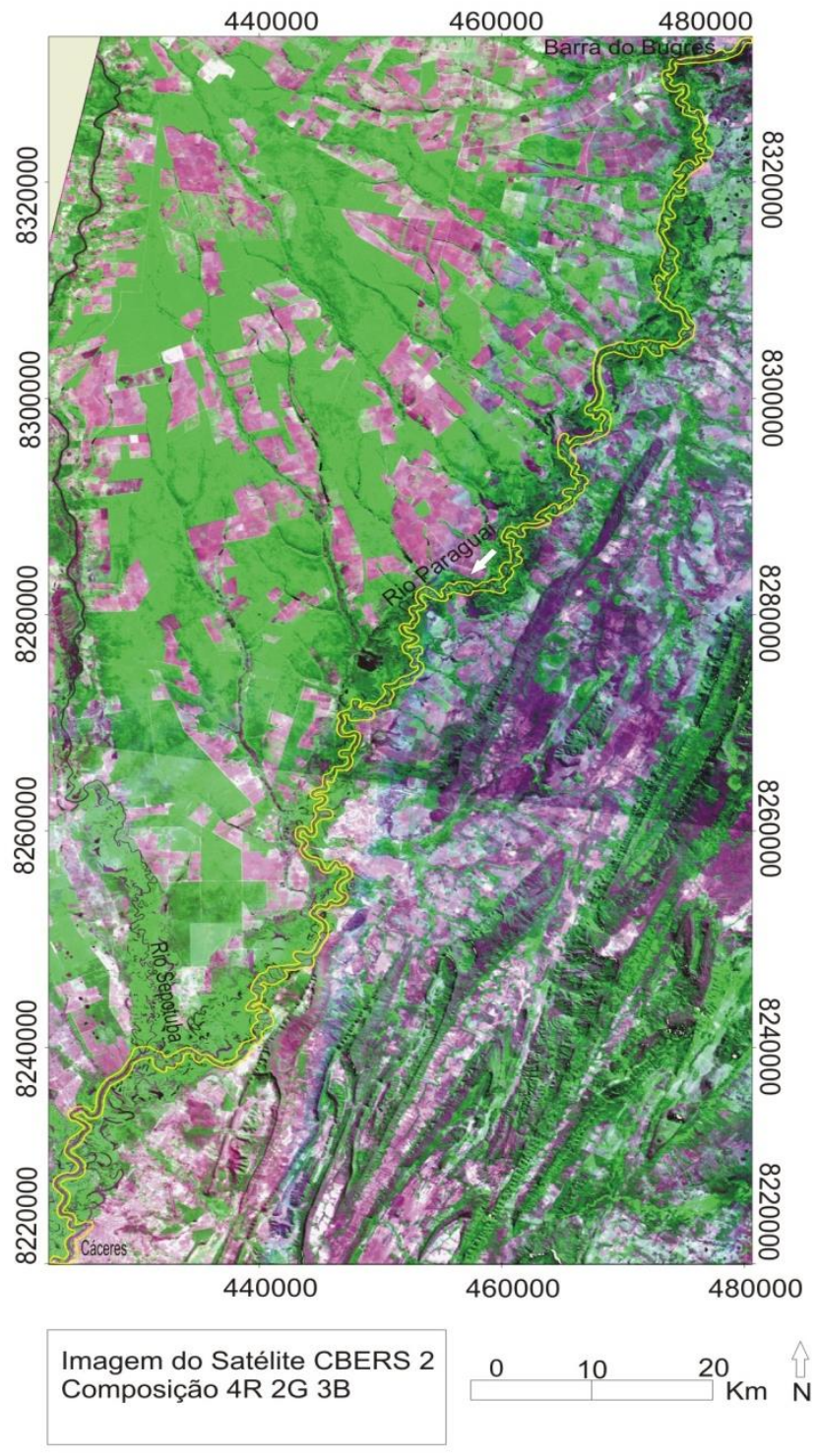

Limite da área de estudo

Figura 1 - Localização da área de estudo. Elaboração: GRIZIO, E. V. 2008. 
$\mathrm{Na}$ área de estudo há três estações fluviométricas disponíveis (Tabela 1). A de Barra do Bugres está situada na parte montante do segmento, a de Cáceres está situada a 150 quilômetros rio abaixo e a Descalvados está situada 132 quilômetros rio abaixo a jusante de Cáceres.

Tabela 1 - Estações Fluviométricas analisadas. Fonte: ANA Agência Nacional de Água. Elaboração: GRIZIO, E. V. 2008.

\begin{tabular}{|l|l|l|l|}
\hline & \multicolumn{1}{|c|}{ Barra do Bugres } & \multicolumn{1}{c|}{ Cáceres } & \multicolumn{1}{|c|}{ Descalvados } \\
\hline $\begin{array}{l}\text { Código da } \\
\text { Estação }\end{array}$ & 66010000 & 66070004 & 66090000 \\
\hline Latitude & $15^{\circ} 04^{\prime} 36^{\prime \prime} \mathrm{S}$ & $16^{\circ} 03^{\prime} 47^{\prime \prime} \mathrm{S}$ & $16^{\circ} 44^{\prime} 00^{\prime \prime} \mathrm{S}$ \\
\hline Longitude & $57^{\prime} 10^{\prime} 57^{\prime \prime} \mathrm{W}$ & $57^{\circ} 41^{\prime} 16^{\prime \prime} \mathrm{W}$ & $57044^{\prime} 53^{\prime \prime} \mathrm{W}$ \\
\hline Altitude & $140 \mathrm{~m}$ & $109,34 \mathrm{~m}$ & $99 \mathrm{~m}$ \\
\hline $\begin{array}{l}\text { Área de } \\
\text { drenagem }\end{array}$ & $10120 \mathrm{~km}^{2}$ & $32774 \mathrm{~km}^{2}$ & $48360 \mathrm{~km}^{2}$ \\
\hline
\end{tabular}

As características climáticas e o regime de débitos foram analisados a partir das séries históricas das estações pluviométricas e fluviométricas existentes na bacia.

Dois grandes momentos interligados e simultâneos marcaram o processo de investigação: a) a pesquisa nas estações pluviométricas e fluviométricas das séries históricas sobre vazão/precipitação; b) a aplicação de técnica de tratamento gráfico dos dados, com a montagem dos fichários-imagem.

O fichário-imagem, como o nome está a sugerir, é constituído por certo número de fichas, correspondente ao número de objetos a analisar e conforme as naturezas dos dados sejam, por exemplo, municípios, regiões, propriedades, indivíduos, etc (Araújo \& Cardoso, 1986). Para Araújo \& Cardoso (1986), o fichário-imagem pode atingir até em torno de 1000 fichas (mas os elementos em $X$ não podem ir muito além de quinze ou vinte).

Nas tabelas 2, 3 e 4 observa-se os anos, a vazão e a precipitação da estações de Barra do Bugres, Cáceres e Descalvados, respectivamente.

Tabela 2 - Estação de Barra do Bugres. Fonte: ANA - Agência Nacional de Águas, 2004. Elaboração: GRIZIO, E. V. 2008.

$\begin{array}{lccc}\text { Estação: } & \text { ano } & \left.\text { vazão } \mathbf{( m}^{\mathbf{3}}\right) & \text { precipitação }(\mathbf{m m}) \\ \text { Barra do Bugres } & 1972 & 103,26 & 1671,9 \\ & 1976 & 174,35 & 1638,2 \\ & 1977 & 158,25 & 1852,5 \\ 1978 & 210 & 1774,2 \\ 1979 & 249 & 1782,4 \\ 1980 & 230,33 & 1553 \\ 1981 & 193,5 & 1260 \\ 1982 & 230,54 & 1996,1 \\ 1983 & 212,47 & 1790,9 \\ 1989 & 213,06 & 1369,9 \\ 1999 & 120,74 & 1088 \\ 2001 & 121,52 & 1558,1 \\ 2002 & 157,61 & 1144,4 \\ 2003 & 179,95 & 1602,3 \\ 2004 & 144,27 & 1137,9 \\ 2005 & 126,72 & 1257,4\end{array}$

Tabela 3 - Estação de Cáceres. Fonte: ANA - Agência Nacional de Águas, 2004. Elaboração: GRIZIO, E. V. 2008

$\begin{array}{lccc}\text { Estação: } & \text { ano } & \text { vazão }\left(\mathbf{m}^{\mathbf{3}}\right) & \text { precipitação }(\mathbf{m m}) \\ \text { Cáceres } & 1972 & 353,27 & 1138,7 \\ & 1976 & 550,26 & 1260 \\ 1977 & 515,03 & 1150,7 \\ 1978 & 556,15 & 1242,4 \\ 1979 & 706,52 & 1572,8 \\ 1980 & 681,39 & 1348,4 \\ 1981 & 602,89 & 1421,7 \\ 1982 & 773,55 & 1766,4 \\ 1983 & 695,28 & 1553 \\ 1989 & 653,9 & 687,9 \\ 1999 & 547,81 & 1099,6 \\ 2001 & 486,86 & 1313,8 \\ 2002 & 582,33 & 1028,6 \\ 2003 & 613,77 & 1056,3 \\ 2004 & 507,21 & 1154,5 \\ 2005 & 431,39 & 1272,5\end{array}$

Tabela 4 - Estação de Descalvados Agência Nacional de Águas, 2004. Elaboração: GRIZIO, E. V. 2008.

$\begin{array}{lccc}\text { Estação } & \text { ano } & \text { vazão }\left(\mathbf{m}^{\mathbf{3}} / \mathbf{s}\right) & \text { precipitação }(\mathbf{m m}) \\ \text { Descalvados } & 1972 & 409,21 & 1612,2 \\ & 1976 & 581,85 & 1285 \\ 1977 & 561,95 & 1258,2 \\ 1978 & 579,17 & 1400,3 \\ 1979 & 626,66 & 1370,7 \\ 1980 & 622,65 & 1328,2 \\ 1981 & 587,72 & 1245,9 \\ 1982 & 686 & 1492,6 \\ 1983 & 672,12 & 1161,6 \\ 1989 & 661,27 & 510 \\ 1999 & 643,4 & 1077,8 \\ 2001 & 612,22 & 1305,2 \\ 2002 & 575,32 & 969,2 \\ 2003 & 666,7 & 843,4 \\ 2004 & 642,3 & 1213,3 \\ 2005 & 654,45 & 257,6\end{array}$

Nas tabelas 5, 6 e 7 foi aplicado o tratamento gráfico de dados, utilizando o método de fichário-imagem. Neles podem verificar os valores de precipitação e vazão. As informações foram extraídas das tabelas 2, 3 e 4, respectivamente.

As categorias "vazão", "precipitação" foram ordenadas. Tanto a precipitação quanto a vazão tem os seus valores representados com cores escuras nas tabelas. Os intervalos dos números de classes, foram definidos tendo em vista a existência de uma grande variação nos índices tanto de vazão quanto de precipitação entre as estações estudadas, optou-se por adotar intervalos de classes de 200, mantendo-se um padrão na apresentação e análise dos dados. 
Tabela 5 - Aplicação do tratamento gráfico de dados. Elaboração: GRIZIO, E. V. 2008.

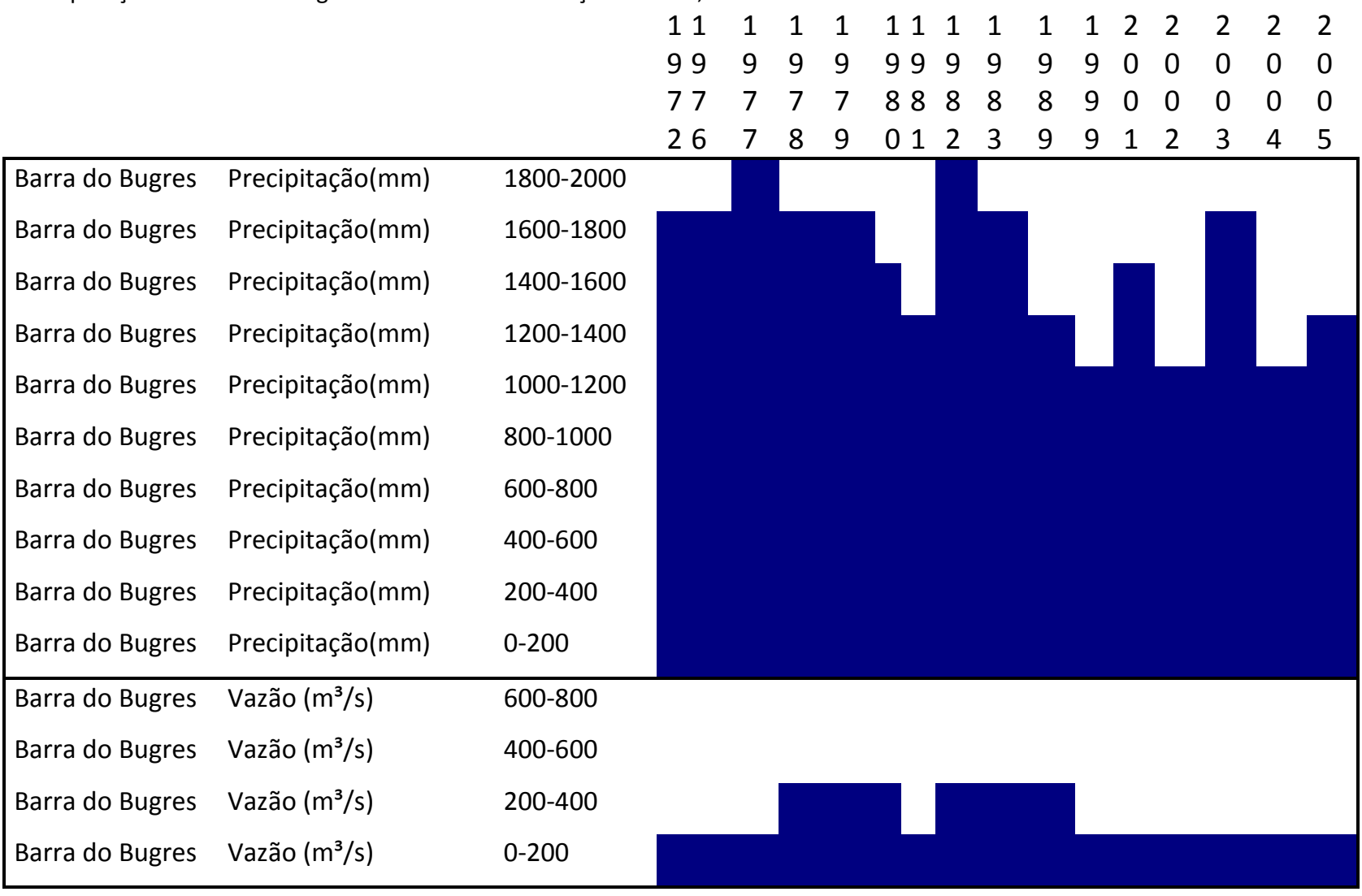

Tabela 6 - Aplicação do tratamento gráfico de dados. Elaboração: GRIZIO, E. V. 2008.

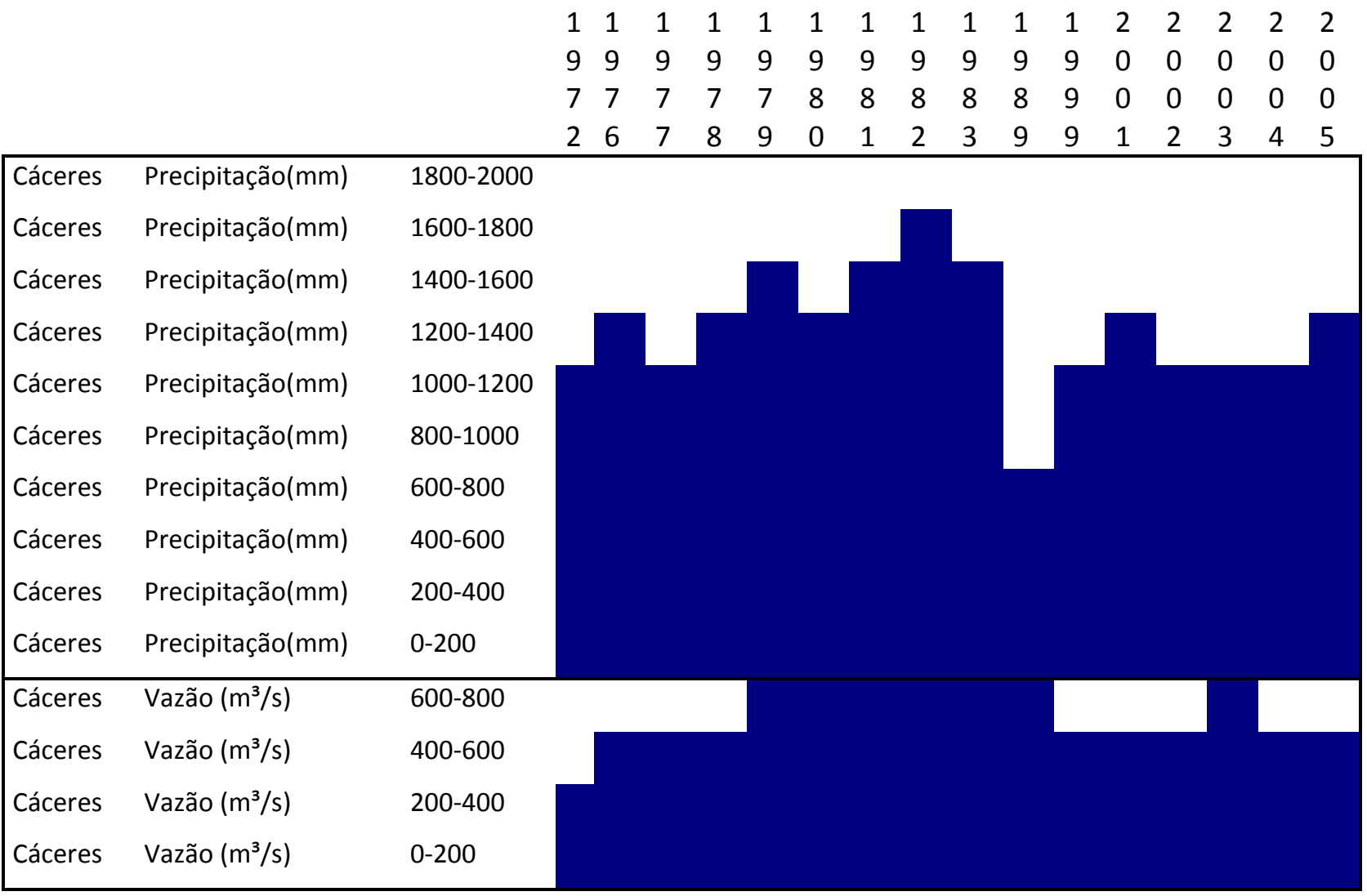


Tabela 7 - Aplicação do tratamento gráfico de dados. Elaboração: GRIZIO, E. V. 2008.

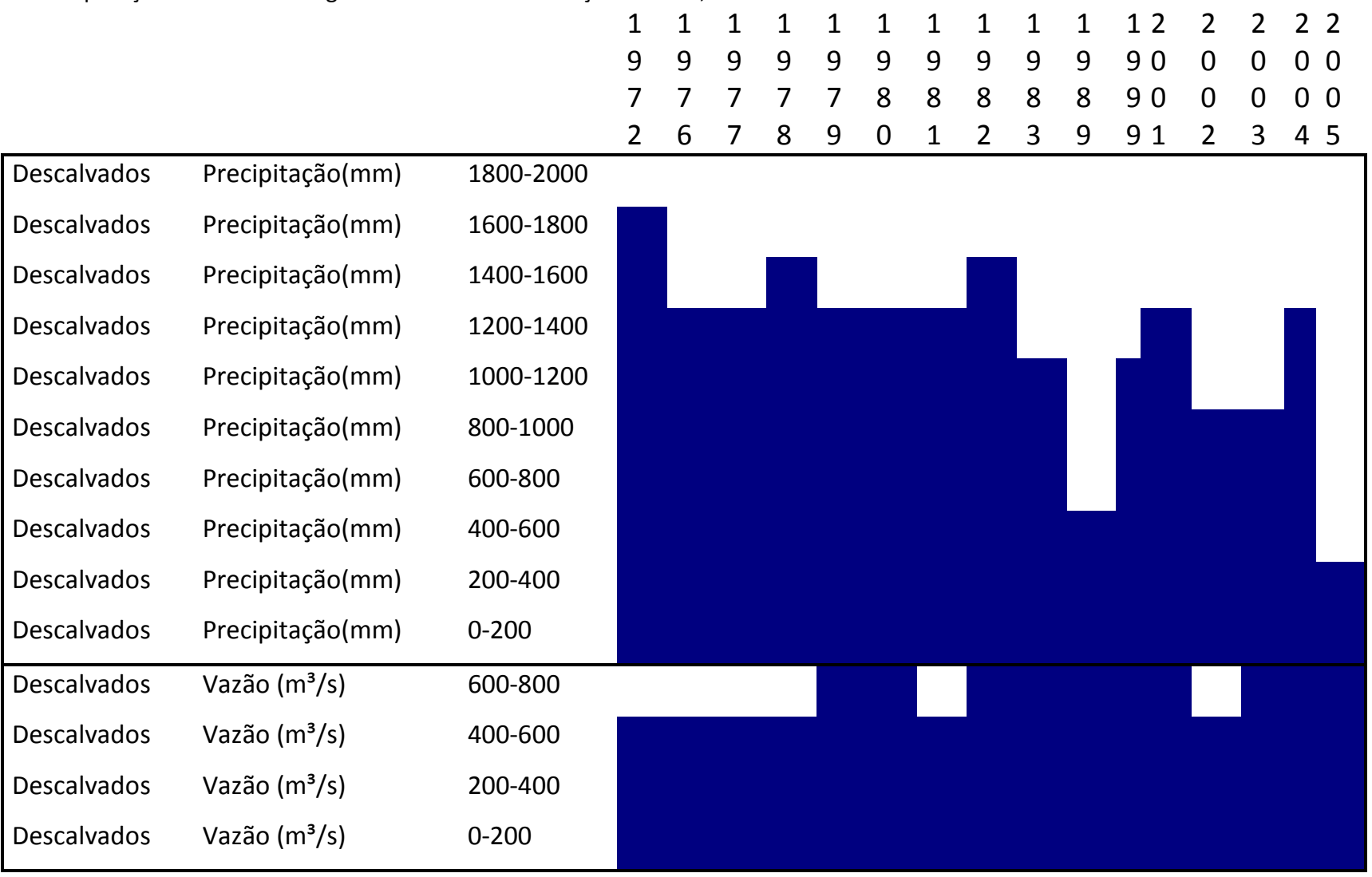

Foram formuladas três tabelas, sendo elas das estações de Barra do Bugres, Cáceres e Descalvados, tornam-se uma só tabela, sendo muito mais legível.

O fichário-imagem é a construção normal das tabelass de dados em nível diferencial ordenado, ou seja, quando um componente é ordenado./ diversificado.

Quando a tabela de dados apresenta componentes do nível diferencial num dos eixos, e ordenado no outro, apenas os elementos inscritos no eixo que abriga os componentes do nível diferencial é que são permutáveis. Ordenado é o componente cujos elementos estão unidos numa relação de ordem, ordem esta que é admitida por todos. O que é ordenado não pode ser reordenado, ou então se quebra a estrutura da série. Quando se está diante de seletivo/ordem ou seletivo (significa diversidade) $X$ ordem diferencial ordenado, é possível transformar o tabela de dados num fichário-imagem. Quando se está diante de diferencial ordenado, é possível transformar a tabela de dados num fichário-imagem.

Trata-se, então, de definir por primeiro a finalidade da construção; em seguida, identificar as características dos componentes que serão representados, e finalmente escolher qual ou quais as variáveis visuais que melhor transcreverão tais componentes.

De acordo com Bertin (1986), para melhorar sensivelmente a legibilidade do fichário-imagem, pode-se, nas grandes séries quantitativas, tomar como eixo a média ou um número médio qualquer.

\section{Resultados e discussões}

A diminuição do valor de montante para jusante indica que à medida que a área de drenagem aumenta, a contribuição do fluxo de base para a manutenção da descarga fluvial também aumenta. Contudo, deve-se fazer uma ressalva para o caso de Descalvados, uma vez que o rio perde água para a planície nos períodos de cheia, o que reduz as vazões mais elevadas na estação fluviométrica.

Tal fenômeno está relacionado à perda de água para a planície, fazendo com que os valores de descarga mais elevada não sejam registrados na estação.

É preciso notar que a vazão aumenta muito lentamente. A resposta lenta do aumento da descarga deve estar relacionada a um elevado tempo de concentração, visto que a bacia de drenagem possui relevo plano, o que favorece a infiltração da água e dificulta o escoamento superficial, e possui depósitos inconsolidados espessos e permeáveis, o que favorece o armazenamento subterrâneo.

Durante o início do período chuvoso (que inicia em setembro) ocorre o armazenamento da água aportada por meio da precipitação. Neste momento o rio Paraguai ainda se encontra com níveis baixos e a descarga começa a aumentar conforme o fluxo de base aumenta. Dessa forma, 
os valores máximos de cheia vão ocorrer apenas dois ou três meses após o período de precipitação mais intensa.

Uma vez que a resposta do sistema ao aporte de água na bacia não é imediata, é difícil estabelecer uma relação de causalidade entre a precipitação diária ou mensal com a descarga fluvial.

Uma vez que as três estações fluviométricas indicam uma tendência de aumento da vazão, as causas desse aumento não são externas à bacia. Dentre as variáveis envolvidas no controle da descarga fluvial, a única que sofreu modificação foi o uso do solo. Dessa forma é provável que a maior disponibilidade de água para o sistema fluvial esteja relacionado à menor evapotranspiração resultante da retirada da vegetação natural.
Nesse caso, havendo menor perda de água para a atmosfera, há maior disponibilidade de água para o escoamento fluvial, fazendo com que as vazões sejam maiores. Uma vez que a bacia possui uma elevada capacidade de armazenamento subterrâneo, a água que não foi para a atmosfera pode manter um fluxo de base mais intenso, proporcionando valores mais elevados de descarga fluvial nos períodos de estiagem (Tabela 8, 9 e 10). $\mathrm{O}$ aumento da quantidade de água armazenada no subsolo está relacionado à elevação do lençol freático, e mudanças na paisagem. Uma dessas modificações é o aumento de água nas lagoas existente na planície e nos terraços da bacia.

Tabela 8 - Dados de vazão e precipitação. Elaboração: GRIZIO, E. V. 2008.

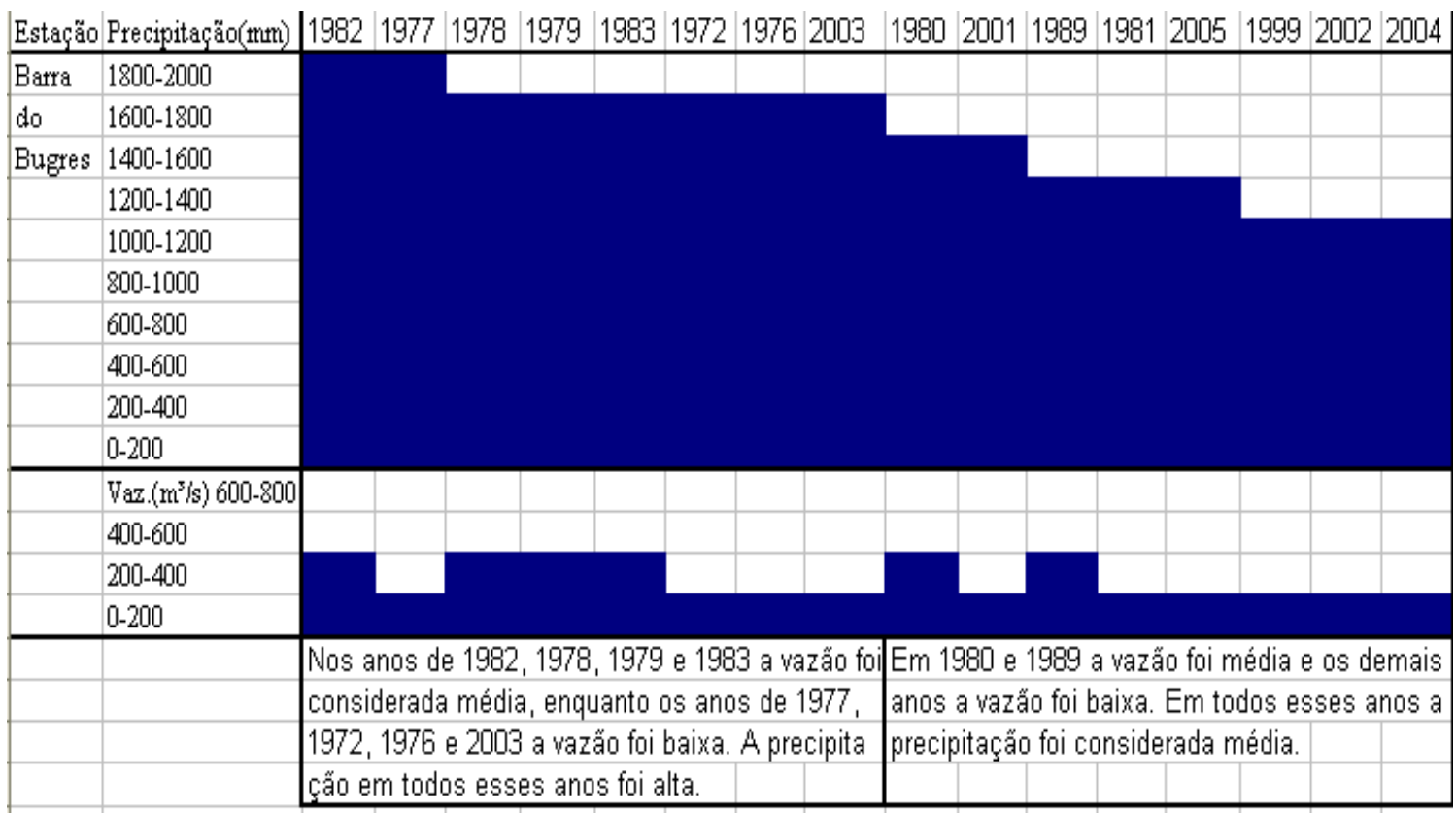

Tabela 9 - Dados de vazão e precipitação. Elaboração: GRIZIO, E. V. 2008.

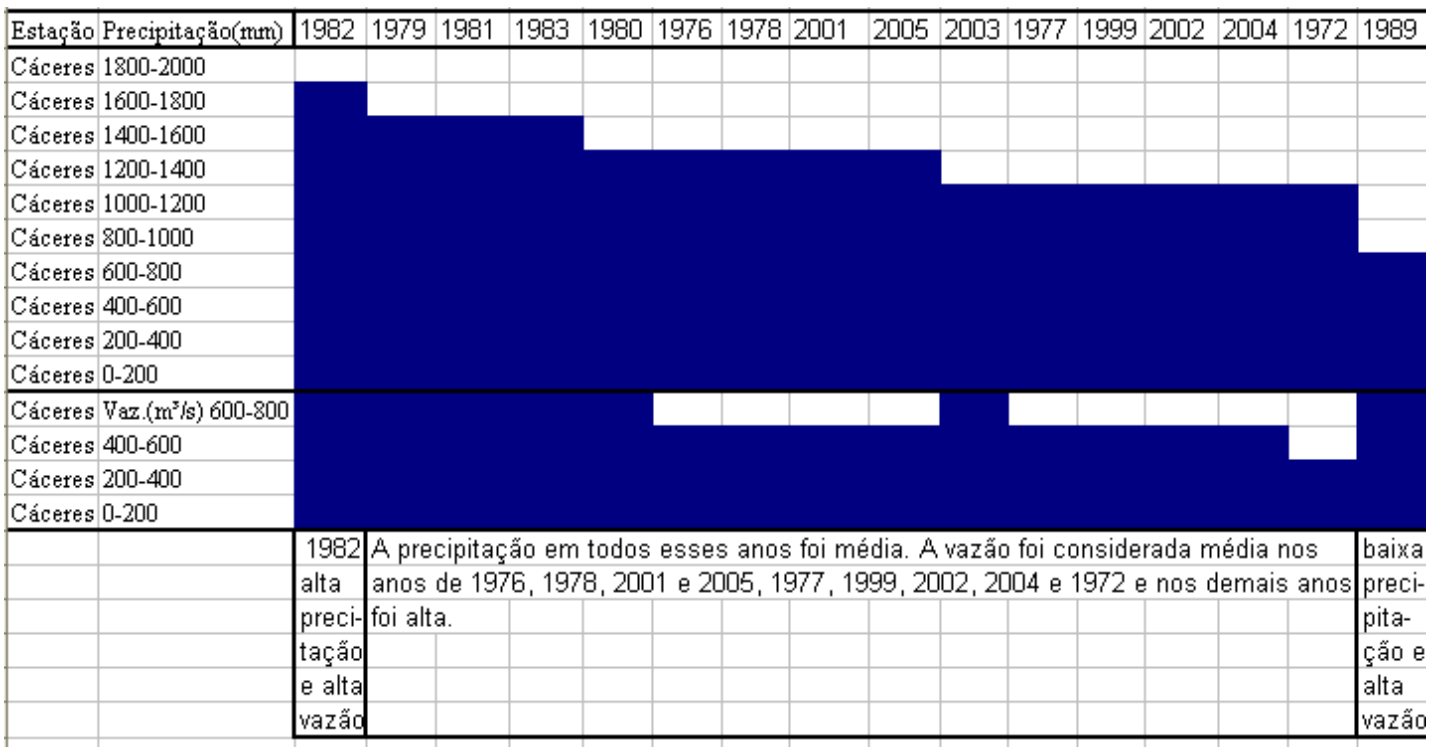


Tabela 10 - Dados de vazão e precipitação. Elaboração: GRIZIO, E. V. 2008.

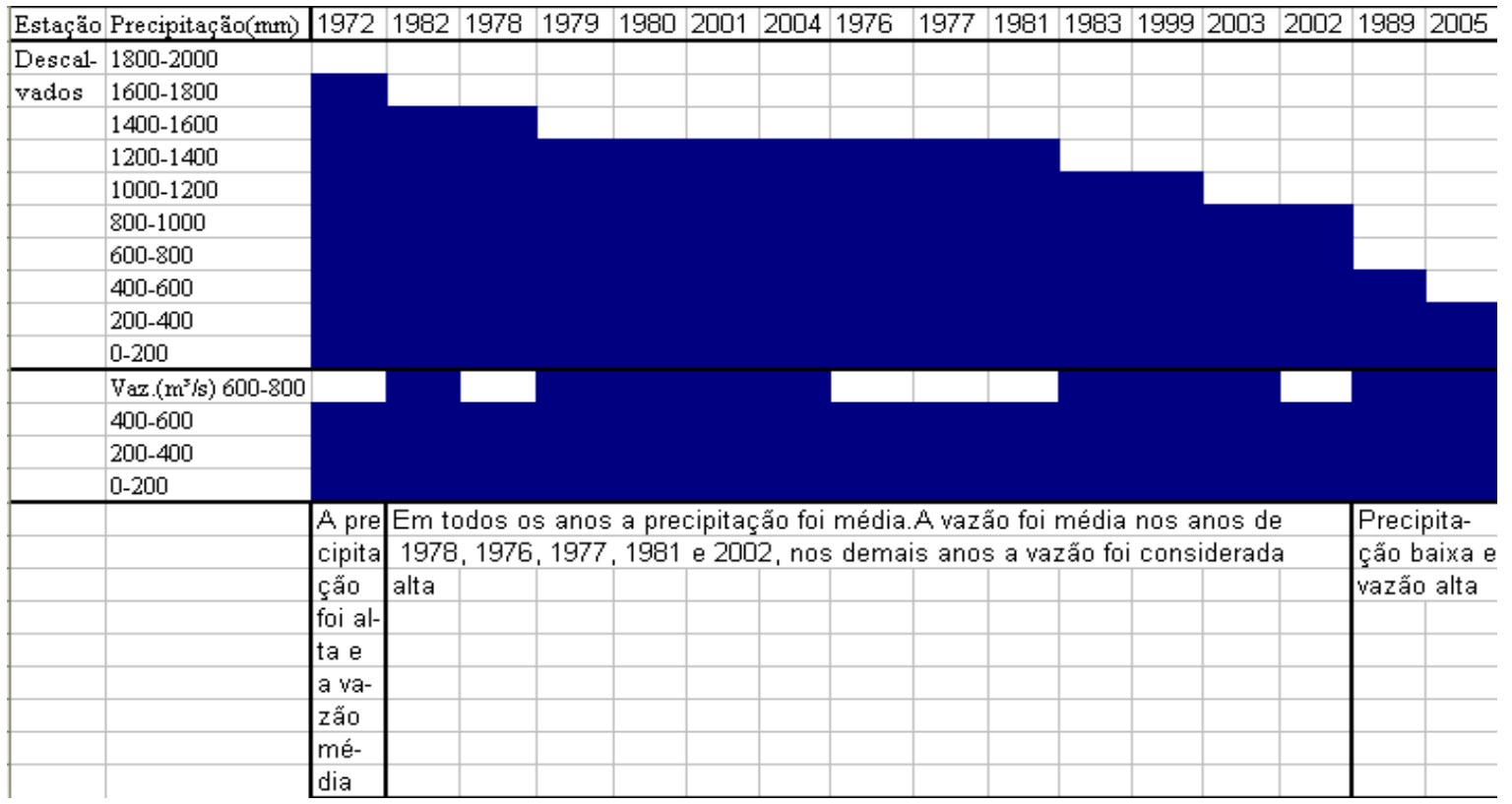

\section{Conclusão}

A técnica utilizada nesse trabalho foi o fichário-imagem que é um dos instrumentos para tratamento gráfico de dados e está contribuiu para a análise das informações.

E foi possível concluir que, o sistema fluvial é marcado por uma resposta lenta à precipitação, o que pode ser explicado pela forma da bacia, pela baixa declividade das vertentes, e pela grande capacidade de armazenamento das coberturas superficiais.

O aumento da descarga fluvial observado ao longo do período não teve causas externas á bacia, portanto, ela deve-se a modificação de uma ou mais variáveis relacionadas ao balanço hídrico. Nesse caso, a variável que sofreu modificação significativa foi a cobertura vegetal. A retirada da vegetação natural e a implantação de pastagem deve ter provocado uma redução da evapo-transpiração, o que permitiu uma maior disponibilidade de água para a alimentação do sistema fluvial. A elevação do nível do lençol freático está relacionada ao aumento da quantidade de água armazenada no subsolo e das mudanças na paisagem, indicada pelo aumento da área das lagoas existentes na planície e nos terraços da bacia.

\section{Referências bibliográficas}

ANA - Agência Nacional de Águas. 2004. Rede hidrometeorológico básica. Brasília. Disponível em: <http://www.ana.gov.br>. Acesso em: 14 de maio de 2004.

ARAÚJO S.M.P., CARDOSO J.A. 1986. O gráfico como instrumento de pesquisa: o fichário-imagem. Curitiba.

BERTIN J. 1973. Semiologia Graphique. Paris, Mouton.

BERTIN J. 1986. A Neográfica e o Tratamento Gráfico da Informação. Tradução de Célia Maria Westphalen. Curitiba: Universidade Federal do Paraná.

BERTIN J. 2000. A Neográfica. Tradução: Jayme Antonio Cardoso. Curitiba: Universidade Federal do Paraná.

TUCCI C.E.M. 2002. Regionalização de vazões. Porto Alegre: Ed.da UFRGS, p. 256.

VILLELA S.M., MATTOS A. 1975. Hidrologia aplicada. São Paulo: McGraw-Hill do Brasil, 237 p. 